Article

\title{
Learning to Learn: towards a Relational and Transformational Model of Learning for Improved Integrated Care Delivery
}

Peter Tsasis $^{1}{ }^{*}$, Jenna M. Evans ${ }^{2}$, Linda Rush ${ }^{3}$ and John Diamond ${ }^{4}$

1 School of Health Policy and Management, York University, Toronto, Ontario M3J1P3, Canada

2 Institute of Health Policy, Management and Evaluation, University of Toronto, Toronto, Ontario M5T3M6, Canada; E-Mail: jenna.evans@utoronto.ca

3 School of Education, University of Manchester, Manchester, England M139PL, UK; E-Mail: linda.rush@manchester.ac.uk

4 Business School, Edge Hill University, Ormskirk, England L394QP, UK;

E-Mail: diamondj@edgehill.ac.uk

* Author to whom correspondence should be addressed; E-Mail: tsasis@yorku.ca; Tel.: +1-416-736-2100 ext. 22171.

Received: 22 April 2013; in revised form: 3 June 2013 / Accepted: 17 June 2013 /

Published: 21 June 2013

\begin{abstract}
Health and social care systems are implementing fundamental changes to organizational structures and work practices in an effort to achieve integrated care. While some integration initiatives have produced positive outcomes, many have not. We reframe the concept of integration as a learning process fueled by knowledge exchange across diverse professional and organizational communities. We thus focus on the cognitive and social dynamics of learning in complex adaptive systems, and on learning behaviours and conditions that foster collective learning and improved collaboration. We suggest that the capacity to learn how to learn shapes the extent to which diverse professional groups effectively exchange knowledge and self-organize for integrated care delivery.
\end{abstract}

Keywords: integrated care; health services integration; complex adaptive systems; learning to learn; self-organization 


\section{Introduction}

Most contemporary health and social care delivery models incorporate the concept of integration, a reform strategy long hailed as a means for improving efficiency, quality of care, and the patient experience [1,2]. By bringing together multiple professionals, services, and organizations, integration efforts aim to replace fragmented care with care that is coordinated and patient-centered [3]. Fragmented care is a consequence of increasing differentiation, specialization and professionalization of health care systems, historical governmental provisions which have separated health care from social services, and shifts in the population's care needs from treatment for acute episodes of illness to management of complex chronic diseases and multi-morbidities [4].

The development of integrated care is a multifaceted and demanding learning process for those involved, where knowledge is an ongoing product of practice created and diffused across professional and organizational boundaries through interaction and dialogue [5-7]. Although efforts to integrate health and social care inherently involve knowledge exchange and creation, a learning perspective is rarely applied in conceptual or empirical studies of integration [8-13]. Most integration efforts and research focus instead on the redesign of organizational structures and processes $[14,15]$. This emphasis may be attributable to traditional models in the literature which conceptualize integration within a linear structure-process-outcomes framework [16-19]. More recently, attempts have been made to address this gap by considering integration as occurring in overlapping phases: (1) initiative and design, (2) experimental and execution, (3) expansion and monitoring, and (4) consolidation and transformation [20,21]. In this process-centered model, the importance of trial-and-error, reflection, and collaborative learning are explicitly highlighted, but not unpacked and explored; the model also retains the linear framing of earlier views of integration. In general, existing models overlook the dynamic complexity of the integration process as a self-organizing phenomenon in which collective learning is emergent and non-linear [22].

In complex systems not everything that occurs does so by design [23] and thus the capacity to learn - rather than the capacity to predict-must be cultivated [24]. It is our premise that collective action as it relates to integration is dependent on collective learning in the context of institutionalized values, structures, and social interactions whereby individuals mutually define each other's roles as a function of relations. Visse and her colleagues, for example, conceptualize integration as a "moral learning process” in which people interactively assign, re-interpret and re-negotiate their identities, relations and values [12]. We thus, take a relational approach to integration where learning and change are attributed to interrelations and not coercive policies, intervention or reorganization.

A learning lens requires attention to the importance of integrating different types of knowledge in the establishment and interpretation of meaning; often, in health and social care, the focus is on the challenge of bringing together professionals with conflicting paradigms rooted in differing subject or technical knowledge and professional experiences [12,13,25]. The boundaries between professional groups and organizations produce strong social and cognitive barriers that facilitate learning within boundaries, but make knowledge "sticky", or difficult to move, across boundaries [26-28]. Due to these barriers, professionals learn to reach their goals within the context of their existing paradigm, ignoring claims to knowledge from others outside their paradigm [29,30]. Cognitive disorder and ambiguity are common as individuals struggle to "make sense" of other actors and organizations, and 
of their current and future relationships [9,31-33]. Conflicts and rivalry also emerge in the integration process, fuelled by perceived threats to professional identity and status [10,11,34,35].

A focus on the challenges of integrating technical knowledge, while important, ignores the roles of individual and collective learning behaviours and learning conditions that can enable professionals to become open and active learners in the face of cognitive and social barriers to knowledge exchange and synthesis. We need to understand how learning and knowledge can be shared across settings within the system and how new knowledge can emerge through the experience of relating with others. In the pages that follow, we frame our work using the principles of complex adaptive systems theory and develop a preliminary learning model to guide future research and practice aimed at understanding and improving how professionals and organizations "learn to learn” in integrated care settings.

\section{Theoretical Framework: Complex Adaptive Systems}

Ongoing challenges to integrating professionals and organizations, and to achieving integrated care [36-38], have prompted the application of complex adaptive systems (CAS) theory to the design, implementation, and management of integrated care [39-42]. CAS are open systems with fuzzy boundaries comprising numerous, diverse and highly interactive agents, including individuals, groups, and organizations; the functioning of the system is a result of the patterns of interactions among these agents $[23,43,44]$. The continuous adaptation of agents and their relationships often contribute to novel and unpredictable behaviours and events which no single agent can know or predict; CAS are thus characterized as non-linear, emergent, and self-organizing [43,45,46].

Such thinking resonates very closely with cultural-historical understandings of learning in which an individual's changing relationship with their environment contributes to new structures of 'consciousness' [47], which in turn alter the individual's relationships with their experienced reality. In this 'social situation of development', defunct relationships fade away and new ones are formed so that the individual becomes repositioned within the practices they inhabit. There is a dialectical relationship between the organisation and unmet needs of the individual and the demands of the practices, which foster learning and ongoing adaptation [48].

Though rarely explicitly mentioned, learning is a common underlying theme in recent studies of integration that apply a CAS perspective. For example, an ethnographic study in an emergency department revealed that inter-departmental and inter-organizational processes of communication, decision-making, and integrated care delivery were best understood using a CAS lens—with care conceptualized as "management of the patient trajectory within porous, shifting, and negotiable boundaries" rather than a linear continuum of care across specialties and settings [41]. Edgren and Barnard used CAS theory to outline recommendations for leaders of integrated care initiatives; the authors suggest that leaders should decentralize control of budgets and resource allocation decisions, emphasize team-building and experimentation, promote the free flow of knowledge and information, and involve patients and their caregivers as co-producers of health [40]. Finally, Tsasis and his colleagues draw from focus group data to argue that the lack of widespread success in integrating care may be explained by "command-and-control" management approaches and rigid long-standing structures that inhibit the capacity of those within the health care system to self-organize [42]. 
Through its emphasis on interactions, CAS theory offers a unique and useful lens for considering how diverse professionals collectively learn and thereby create new relationships and behaviours. This phenomenon is referred to as "self-organization”, defined as the spontaneous emergence of new structures and behaviours without external control or intervention [49-51]. Scholars agree that in social systems self-organization occurs as a response to continuous feedback from changing patterns of relationships among agents, and interactions between these agents and their environment [23,52]. Since everything is interconnected so that one agent's actions changes the context for others, and patterns of interaction are influenced by constantly evolving local needs, formal rules, procedures and structures are unable to effectively address and manage change [53]. Through positive self-organization, social structures emerge which better address the challenges at hand, such as the changing needs and capacities of agents in the system or the changing demands and opportunities of the environment [54]. Attempts to force or prescribe change are often counter-productive in CAS due to the potential to destabilize the system [24,55]. A CAS perspective thus contrasts sharply with traditional theories of management, which promote orderly planning, forecasting, and control.

Several recommendations have been provided for how to facilitate self-organization in social systems, including: facilitative and distributed leadership; open communication channels, continuous flow of information, and clear feedback mechanisms supported by information technologies; organizational structures that are not too rigid and supervised; frequent opportunities for interaction and interprofessional dialogue; and ongoing experimentation and reflection [23,40,52-54,56,57]. These recommendations have a shared emphasis on learning, sensemaking (the process by which people give meaning to experience), and knowledge co-creation $[23,53,58]$, which suggests that these are key themes inherent in the self-organization process. In fact, Comfort refers to self-organization as the "learning capacity" of a social system [54,59].

CAS theory suggests that the capacity to self-organize for integrated care delivery is inherent in the collective intelligence of agents within the system as agents interact and relate to each other. Excessive control mechanisms are unnecessary and potentially counter-productive [60]. This is not to suggest that there is no place for leadership, structures, and planned change; on the contrary, leaders play a key role in creating an environment and work context that facilitates, rather than hinders, the capacity of heterogeneous professional groups to self-organize in ways most meaningful to them [24,59,61-63].

Although the behaviours of CAS are unpredictable in their trajectory, they can be understood in terms of their patterns of meaning and behaviour [23], by focusing on collective knowledge and learning. Knowledge can be both a noun and a verb; it can be codified and transferred (explicit knowledge), but it is also emergent and in a constant state of change, making it difficult to write down or transmit (tacit knowledge) [64]. Cook and Brown call what is possessed or held in the head, 'knowledge', and what is part of action and interaction, 'knowing' [65]. Knowledge differs from information in that it contains the interpretation and framing of the knower [52,66,67]. Knower and known engage in a dialogue and as a result, both may experience change in understanding as a new perspective may emerge from the specific context of the interaction [12]. New knowledge and new ways of knowing emerge when knowledge is used as a tool for knowing through productive inquiry. To be engaged in productive inquiry is to be actively pursuing a problem, puzzle, point of fascination, object of wonder, or the like, and to seek an answer, solution or resolution [68]. Productive inquiry is the first step towards the reciprocal exchange of knowledge, or "perspective taking", through which 
health and social care professionals can confront, modify, and/or combine knowledge with the possibility of creating innovative thinking and work practices [28,69,70].

We argue that examining and understanding how interprofessional groups in the health and social care system learn with, from, and about each other (or fail to do so) can provide insights into the selforganization process, and thus help us better understand the relational enablers and barriers to achieving integration. This perspective raises the question, "what are the individual and collective learning behaviours that enable professionals to become open and active learners in the face of cognitive and social barriers to knowledge exchange and synthesis?” In other words, what are the behaviours of a successful learner and the characteristics of an effective learning environment in the context of integrated care efforts?

In the literature on formal education, "Learning to Learn" (L2L) is an alternative pedagogy for exploring knowledge exchange and knowledge creation [71,72]. A successful learner is viewed as one that actively investigates the consequences of new information, detecting and exploiting a variety of learning opportunities to resolve conflicts and to fill knowledge gaps [73,74]. By exploiting learning opportunities (through inquiry and reflection as a function of their actions and interactions with others), the learner is able to learn beyond the explicit content of the new information, thereby expanding their capacity to learn [75]. This is akin to meta-cognition, defined as "the capacity to monitor, evaluate... and change how one thinks and learns"; in other words, meta-cognition is the ability to reflect on one's own learning and intentionally apply the results of one's reflection to further learning [76].

Expanding one's capacity to learn (i.e., L2L) involves a paradigm shift towards a relational and transformational model of learning with attention to (a) traditional academic content, skills and outcomes, (b) learning dispositions, values and attitudes, and (c) learner-, knowledge-, assessment- and community-centered learning environments [77,78]. Ongoing social interactions produce patterns of relating, such as role structures, hierarchies, and cultural norms and patterns of meaning, such as concepts, language and knowledge [79]. As patterns of relating and meaning are continuously re-enacted, they may spontaneously create new patterns (i.e., self-organization). Relational and transformational learning represent a fundamental epistemological change in how we know and understand the world, and typically occurs as a response to external forces or processes, such as an unexpected challenge or event [80,81]. Learning, in this context, is not just informational, represented by the addition of knowledge, but is deep and meaningful with the core learning outcomes leading to transformed ways of knowing, working, and relating [82].

In addition to being used at the individual level, the concept of L2L has also been applied to inter-organizational and interprofessional relations in the education sector; "Partnership Learning to Learn" involves intentional, reflective, and collaborative learning among diverse professionals spanning multiple work settings [83,84]. We propose that L2L may provide a way of re-weaving socio-cognitive webs of knowledge, beliefs and habits of action in interprofessional relations, thereby contributing to positive self-organization and enhanced integration of care.

Based on the challenges to integration and the potential contributions of CAS and L2L perspectives, we make the following two propositions: (1) L2L facilitates collective learning and self-organization towards integration, and (2) L2L must be a key professional competency for managers, clinicians, and other staff working towards integrated care. Below we present a conceptual model of L2L as it applies 
to integrated care efforts, drawing from relevant literature in health care, education, and organizational/system behaviour. This will be followed by a discussion of the implications of this work and suggestions for future research.

\section{Learning to Learn (L2L) for Improved Integrated Care Delivery}

Professionals and organizations often come together with little preparation in terms of what is required to deliver integrated care; leaders and professionals lack the tools or skills for collaborative working [13]. Learning how to learn (L2L) can help interprofessional groups navigate uncertainty, complexity, and exposure to diverse needs and values - all factors associate with delivering integrated care. We define L2L as an ongoing process by which learners move towards relational and transformational learning to achieve meta-cognition (the capacity to monitor, evaluate and change how one thinks and learns). L2L is not a linear process; individuals may move back and forth between various types and depths of learning throughout the integration process. Key learning behaviours and conditions (heretofore referred to as processes) associated with L2L and which we argue help foster self-organization as the learning capacity of a social system include 'interaction', 'feedback', 'reflection' and 'self-directed learning' (Figure 1). Straddling affective, cognitive and relational dimensions, these processes are recognized as much a matter of character as a set of skills, demanding a much richer vocabulary around learning that includes words like attitudes, dispositions, qualities, values, emotional tolerances, norms and habits of mind [85]. Although separated for the purpose of clarity, these processes are inter-related as suggested by the two-way arrows in Figure 1, which connect the four processes. These L2L processes can result in frames of reference that are more conducive to additional amendments and additions, and that are more inclusive and discriminating [86,87]. In other words, L2L can make learners more capable of exchanging knowledge and assimilating new information into existing knowledge, beliefs and habits of action. Through self-organizing processes, learners may begin to change the structure and dynamics of how they interact, creating new sets of linkages across professional and organizational boundaries, consequently enhancing integration [88]. Although L2L can manifest at the individual, group and organizational levels, we focus on the individual and group levels in this paper.

The social, cultural and historical context within which learning occurs plays a vital role in the learning process, in part, through the affordances and demands made on the learner [89-91]. The dynamic tension between the agency of the learner and the affordances of the practice, as played out in each activity, is where learning occurs. The intentional agency of the professional needs to be sustained if she or he is to work on and with the system of relations they are building within their practice [89]. Whether the context and practice is conducive to the exercise of that agency therefore becomes of crucial concern; even young children are intentional and approach activities with the purpose of having an impact of some kind. Therefore, in order to provoke and promote interprofessional learning for integrated care, we need to attend to the demands that integrated care practices and the broader context make on professionals who are also learners.

In the sub-sections below, we explain the four key L2L processes, depicted in Figure 1 and described in Table 1, in further depth and discuss their relevance to integrated care efforts. 
Figure 1. Learning to Learn (L2L): A Conceptual Model of Learning Behaviours and Conditions that Contribute to the Self-Organizing Capacity of Care Systems. There are interconnections between all L2L behaviours and conditions (not all shown).

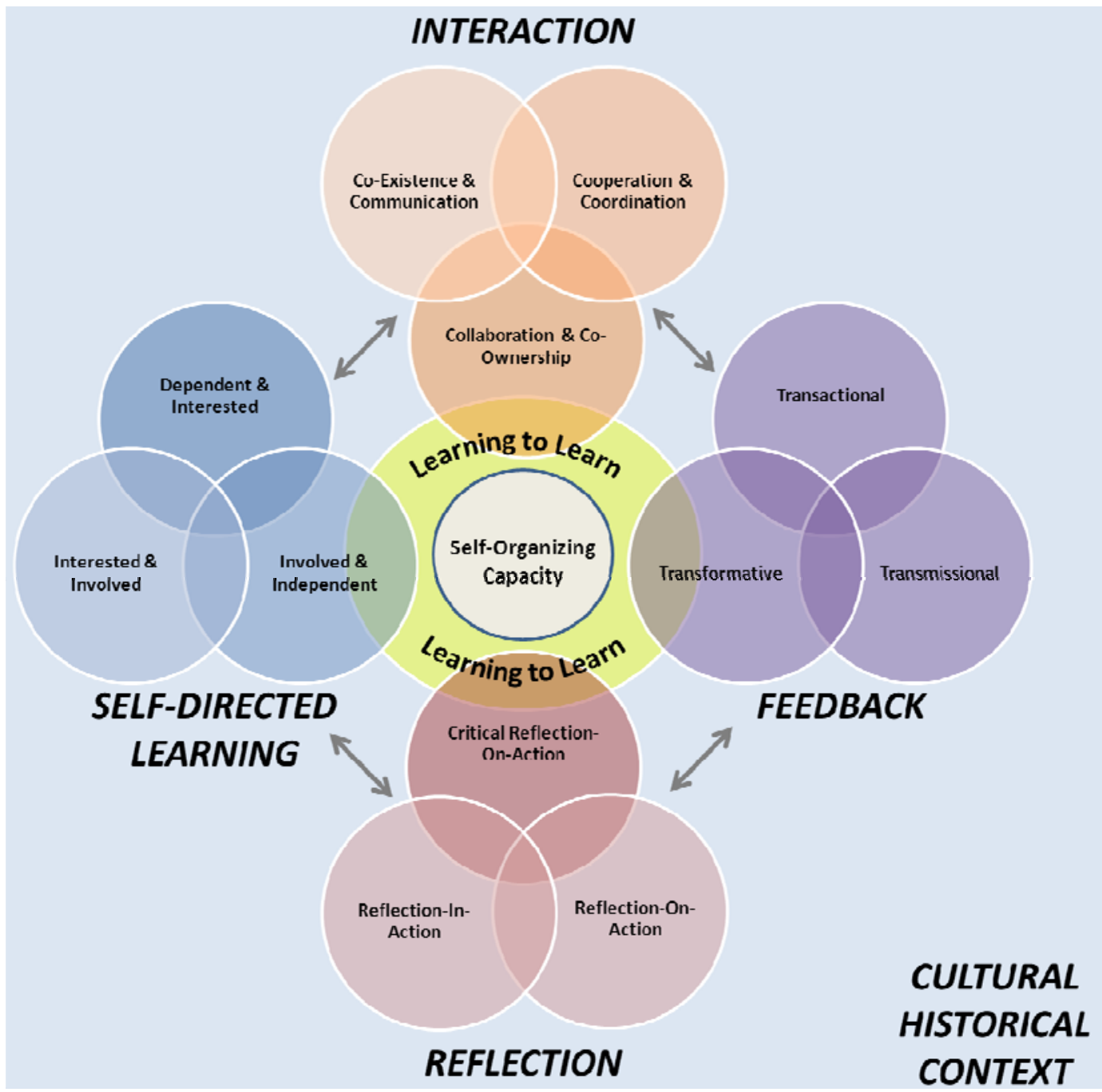

Table 1. Learning to Learn (L2L) Model for Care Systems: Terms and Definitions.

\section{TERM}

Learning to Learn (L2L)
DESCRIPTION

an ongoing nonlinear process by which learners achieve meta-cognition (the capacity to monitor, evaluate and change how one thinks and learns)

\begin{tabular}{|l|l|}
\hline Interaction [92] & minimal interaction and early efforts to get to know one another \\
\hline $\begin{array}{l}\text { Co-Existence \& } \\
\text { Communication }\end{array}$ & working together towards shared goals within defined parameters \\
\hline Cooperation \& Coordination & $\begin{array}{l}\text { high degree of commitment and investment, shared responsibility, and a } \\
\text { willingness to work outside of traditional rules or norms for mutual benefit }\end{array}$ \\
\hline Collaboration \& Co-ownership & $\begin{array}{l}\text { rapid reaction, which often results in a temporary solution or way of } \\
\text { dealing with a situation or problem; usually personal and private }\end{array}$ \\
\hline Reflection [93] & $\begin{array}{l}\text { observation and analysis followed by action to improve the situation or } \\
\text { solve the problem; usually interpersonal and collegial }\end{array}$ \\
\hline Reflection-on-Action &
\end{tabular}


Table 1. Cont.

\begin{tabular}{|l|l|}
\hline TERM & \multicolumn{2}{|c|}{ DESCRIPTION } \\
\hline Critical Reflection-on-Action & $\begin{array}{l}\text { Observation, research, evaluation and theory-testing on an ongoing basis; } \\
\text { usually interpersonal and collegial }\end{array}$ \\
\hline Self-Directed Learning [94] & \multicolumn{2}{|l|}{$\begin{array}{l}\text { requires external direction and support, responds to motivational } \\
\text { techniques }\end{array}$} \\
\hline Dependent \& Interested & $\begin{array}{l}\text { engages in learning independently, but facilitation is required to help } \\
\text { develop confidence, sense of direction, and ability to work with and learn } \\
\text { from others }\end{array}$ \\
\hline Involved \& Independent & $\begin{array}{l}\text { sets goals and standards, continually self-assesses with or without external } \\
\text { help, seeks resources to support learning, and willing and able to take } \\
\text { responsibility for personal learning and productivity }\end{array}$ \\
\hline Feedback [48,95,96] & $\begin{array}{l}\text { transmitted by an authority (knowledge is disconnected and replicated in } \\
\text { practice) }\end{array}$ \\
\hline Transmissional & $\begin{array}{l}\text { acquired through application, experience, and interaction (connections are } \\
\text { made and relationships are appreciated) }\end{array}$ \\
\hline Transactional & $\begin{array}{l}\text { used to actively create and co-create new frames of reference (connections } \\
\text { are understood as a whole and reconceptualised) }\end{array}$ \\
\hline Transformative &
\end{tabular}

\subsection{Interaction}

Interaction refers to the relationships and communication between agents as they exchange experiences and information; these interactions may be verbal, written or electronic, as well as symbolic or nonverbal [52,54]. The basic premise underpinning the notion of interaction is that people are social and make decisions on the basis of social meanings [97]. The interaction process is essentially one of negotiation, with the response of each person at each point being strongly influenced by the response of the other [98]. As such, it is believed that the way one thinks or acts is influenced (mediated) by those around them; behaviour does not emerge, but rather is constructed jointly. Individual characteristics that facilitate and support interaction include reciprocity, empathy, and openness to feedback. Interactions and relationships with others provide a means for renewed thinking through knowledge exchange, experimentation, and collaboration. This is consistent with the work of Olson and Eoyang on teams, where meaningful interaction and discussion among team members with significant differences in level of expertise, functional specialties, and alternative views is essential for successful team integration and cohesiveness [24].

Multiple models of the degrees of teamwork and collaboration exist. We drew from Bailey and Koney [92] and Gajda [99] to group together the most common concepts into three types of relationships: (1) co-existence and communication, (2) cooperation and coordination, and (3) collaboration and co-ownership (See definitions in Figure 1). Inter-organizational and interprofessional relationships characterized by collaboration and co-ownership are more likely to contribute to L2L because of the more frequent and deeper levels of interaction, which enable individuals to co-produce values, roles and relationships by accepting, refuting, re-interpreting, and re-negotiating responsibilities [12]. Through this continuous self-organizing learning process, relational identities are 
socially constructed [100,101] and knowledge is shared and co-created. According to Transactive Memory Theory, developing shared understandings enables individuals with differences in specialized knowledge to draw upon a larger body of collective knowledge, creating a collective mind that is distributed across multiple individual mindsets [102-105]. For example, in a study of the development of an integrated stroke service network, health professionals learned to look beyond the boundaries of their own profession through frequent interaction in which knowledge was created, shared, and utilized [10]. Interaction and dialogue over a two-year period enabled these professionals to "form a mental picture of what goes on in other organizations”, learn how others work and think, and develop collective jargon for managing patient referral [10]. In this case, frequent and focused interactions fostered knowledge integration and the transformation of basic assumptions and dominant logic.

\subsection{Feedback}

Feedback refers to the internal flow of knowledge and information in a system, which can influence patterns of interaction positively or negatively [23,52]. To be effective, feedback should be direct, specific, rapid, constructive, and continuous, reporting on both poor as well as good performances at the individual, group, organization and system levels [106]. Miller and Seller distinguish between three types of learning: (1) transmissional (knowledge transfer), (2) transactional (knowledge sharing), and (3) transformative (knowledge creation) [95,96]. These labels can also be used to describe the mechanisms by which knowledge and information flow across professional and organizational boundaries, and their impact on learning (See definitions in Figure 1). Understanding how feedback from a different professional community or organizational setting fits within the context of one's own work requires transformation—not just transfer—between communities [107].

Feedback mechanisms that are transformative-encouraging co-creation of knowledge through, for example, purposeful dialogue, role playing, story-telling, group coaching, and scenario planning-are more likely to contribute to L2L by providing the knowledge and information needed to challenge the status quo and create a desire for change [56]. Traditional methods of sharing knowledge and information such as educational sessions, training workshops, and written communication, are passive and dyadic, representing more transmissional and transactional feedback mechanisms $[8,13]$. The use of multiple formats and media (i.e., written, oral and visual) as well as group-based approaches such as those suggested above can help foster the kind of feedback loops necessary for effective learning and self-organization [8].

Studies of integrated care efforts highlight the importance of data infrastructure and information systems as well as reflexive monitoring for the purposes of information exchange, performance evaluation, and performance reporting $[8,15,108]$. In the case study of an integrated stroke service network, described above, information and data on patient flows through the care pathway was routinely fed back to professionals (not exclusively managers) who discussed the results as a group to inform collective decision-making and the implementation of small changes to improve care [10]. Because feedback often flows separately to different actors, active and continuous interaction is needed to provide a "dynamically updated integrated picture” of the system and relative performance [56]. 


\subsection{Reflection}

L2L is also facilitated by frequent reflection, defined as "a process of reviewing an experience of practice in order to describe, analyze, evaluate and so inform learning about practice” [109]. Reflective thinking and reflection can be viewed as experiential learning techniques [68]. Reflection often helps to address practical problems by allowing for doubt before possible solutions are reached [110]. In general, reflection involves purposeful critical analysis of knowledge and experience in pursuit of deeper meaning and understanding.

Griffiths and Tann identify two levels of reflection: (1) reflection-in-action and (2) reflection-onaction (See definitions in Figure 1) [93]. Critical reflection-on-action is the most rigorous form of reflection in that it involves observation, research, evaluation and theory-testing on an ongoing basis. This is akin to Eoyang and Holladay's notion of "adaptive action" which involves dealing with uncertainty by systematically reflecting on the questions, “What? So What? Now What?” [111]. These questions facilitate careful observation, consideration of options and implications, and responsible action. There is evidence to suggest that shared reflection, involving small groups or teams, is more effective in influencing understanding and behaviour because it offers information from multiple perspectives; interaction and the use of feedback are fundamental to this process [112].

Schon introduced the concept of the "reflective practitioner" as one who uses reflection to revisit experience both to learn from it and to help frame complex problems of professional practice [113]. Reflective capacity is regarded by many in the health care sector as a key aspect of professional competence [114]. Although some people are naturally more reflective than others, reflection is a skill that can be learned, practiced, and refined given appropriate guidance and support [114,115].

In the context of integration efforts, reflection can help professionals build integrated knowledge bases that link new to existing knowledge. Deeper levels of reflection help to move individuals and teams from "routinely doing" to looking critically at practice [116]. For example, evaluation of the English Integrated Care Pilots suggest the following cognitive enablers of integration: understanding how new practices and processes differ from those used previously; understanding how individuals' specific tasks and responsibilities will change; agreeing on aims and objectives; and developing a shared understanding of the benefits and importance of integration [108]. These are well-known influencing factors in the literature on integration [2,32] and achieving them inherently involves some level of both individual and collective reflection-on-action.

\subsection{Self-Directed Learning}

Self-directed learning is closely allied with the concept of metacognition, which is concerned with knowing how you know things and the processes by which you think you know [117]. Integral to metacognition are the concepts of self-regulation and individualization. Self-regulation implies “autonomous learning, being able to prepare and supervise one's own knowledge acquisition, provide one's own feedback and to keep oneself concentrated and motivated” [118]. Individualization, Freeman explains, has to do with an individual being given and assuming greater responsibility for the content and pace of their own progress [118]. Self-directed learners typically have a preference for challenging work, high persistence in the face of difficulty, and a focus on learning as a goal in 
itself [119-121]. Self-directed learners are also more likely to use effective learning strategies to monitor their own learning, check that they understand the meaning of their work, and relate learning in formal education to their own experience [122].

Grow's model of self-directed learning outlines four types of learning dispositions: (1) dependent, (2) interested, (3) involved, and (4) self-directed or independent (See definitions in Figure 1) [94]. While dependent learners need explicit directions from an authority figure on what to do, how to do it, and when, self-directed or independent learners set their own goals and standards, with or without external help, and exercise skills in time management, self-evaluation, and peer critique.

Reflective capacity plays an integral role in self-directed learning; the ability to self-evaluate depends on the ability to reflect effectively on one's own practice, while the ability to reflect effectively requires accurate self-evaluation [114,123]. A quality management model for integrated care developed by Minkman and her colleagues consists of nine key themes, one of which is "result-focused learning” [20]. This theme emphasizes the collaborative exchange of knowledge, information, and feedback as a means for enabling continuous assessment and improvement of practice. Result-focused learning is enhanced by the presence of individuals and teams capable of and motivated to engage in reflection and self-directed learning. While individual characteristics, such as being proactive, observant, flexible, and curious, facilitate self-directed learning, external encouragement and support and peer assessment may be required since professionals may be unaware of potential gaps in their knowledge and therefore may not perceive a need for further learning [124]. Although self-directed learning focuses primarily on the individual learner, it is a process that may also manifest at the group and organizational levels and is most effective when supported and enacted at the point of practice, which is where learning occurs [125]. As alluded to above, self-directed learning, reflection, feedback and interaction are not stable skills or conditions; they are situationally-bounded cognitive and social processes that are context specific [126]. Organizational context, including structures, leadership and culture, strongly influences the development and enactment of these L2L behaviours and thus can be designed to facilitate their emergence [127-130].

\section{Discussion and Conclusions}

In this paper we propose that integration be reframed as a learning process, and professionals and their organizations reconceptualized as learners operating within complex adaptive care systems. We make three inter-related arguments. First, we propose that examining and understanding how interprofessional groups in integrated care settings learn with, from, and about each other (or fail to do so) can provide insights into the enablers and barriers to achieving integration. Second, we draw from CAS theory to highlight the dynamic complexity of care delivery and to introduce self-organization as the mechanism by which integrated care is achieved and delivered. Finally, we suggest that the capacity to learn how to learn may be a key factor shaping the extent to which diverse professional groups and organizations effectively exchange knowledge and self-organize. Figure 1 provides a starting point for considering learner behaviours and learning conditions as they relate to the development and self-organization of integration initiatives.

The key question is: how can health and social care organizations become settings in which the various constituent elements of learning capacity are acknowledged, discussed, understood and 
systematically strengthened? There are two avenues for change. The first is upstream within educational institutions providing early and continuing professional education. Changes may be implemented to the way health care professionals educate, practice, and socialize into their profession. The idea of "situated agency" re-enforces the need to explore the ways in which individuals and groups are prepared for different professional settings: what constitutes knowledge and skills, and how professional identities are assumed, absorbed as well as contested by other professionals and/or service users. However, education reform is challenged by the institutional structures of universities and medical schools which historically resist change and emphasize research and research entrepreneurship over teaching and education [35].

The second avenue for change, and the one which we focus on, is downstream at the point of practice within health services organizations. The learning environment within and across organizations must be designed and cannot rely on spontaneous interactions and the flow of everyday work. Opportunities for abstraction, pattern-seeking, and looking beyond the experience of everyday practice are needed [131,132]. Integration initiatives are often implemented in the context of rules, regulations and hierarchical ways of working, thereby reinforcing the constraints of professional disciplines, cultures and practices [36,133]. The literature on learning theory describes an effective learning environment as one that is learner-centered, knowledge-centered, assessment-centered, and community-centered [78]. Learner-centred refers to environments that pay careful attention to the knowledge, skills, attitudes and beliefs of learners, and the demands that the task (in this case integration) makes on learners. Knowledge-centred environments focus on the learners' understanding of the structure and content of the subject, how the subject works and what its big ideas are, and how to apply their skills in that context. Assessment-centred environments provide frequent and detailed formative feedback to learners. Finally, community-centred environments recognize that classrooms or work settings are embedded in a larger community; external social, economic, and political factors are explicitly considered in the design and implementation of learning strategies.

In health care, there is an over-emphasis on knowledge and skill (the formal role as opposed to the person or learner) and a tendency to use performance measurement for punitive purposes. Most health care teams, organizations and networks, therefore, have failed to create effective learning environments. A focus on professionals as learners, the use of feedback for the purpose of learning, and the incorporation of community voices (such as patients and caregivers) may help create more balanced learning environments in which the habits of interaction, feedback, reflection, self-directed learning, and systems thinking are cultivated.

From a CAS perspective, learning environments arising from reflexive interactions lead to adaptation among a group of actors [134] and organizations [135] as actors reflect on their experiences, and recognize new patterns of relationships that facilitate sense-making of their actions [136]. Learning from sharing feedback reinforces the emergence of these patterns, locking them into micro-social systems which are socially constructed [137], and nested within the larger system. Through the L2L behaviours and conditions (Figure 1), individuals are capable of learning, gaining new shared understanding, and at times, breaking from their own mental logics in forming a more coherent response. Self-organizing patterns surface when there is enough structure to give the group identity and coherence thus leading to the emergence of new patterns of behaviours to an evolving 
social context [110]. This is characteristic in CAS of adaptation and co-evolution within and between micro-social systems [135,138].

CAS theory and the literature on formal education suggest several strategies for strengthening L2L at the level of work-based practice, including modifications to language, explicitly designing activities and work practices to encourage learning through interaction and reflection, the use of teamwork and experimentation, creation of an open 'space' for sharing feedback, and the modeling of desired learning dispositions by leaders and managers [23,40,52-54,57,63,73,139,140]. Through such interventions, problem-solving communication is encouraged and shared goals, shared knowledge and mutual respect may be fostered to produce relational coordination among professionals [141,142]. Like CAS theory, the concept of relational coordination emphasizes the importance of understanding relational patterns and using that information to help design interventions that foster and encourage the development of new patterns of interactions and behaviours. A validated tool is available for measuring and analyzing the communication and relationship networks through which work is coordinated among professionals. The high-level snapshot of relational coordination provided by this tool may be complemented by exploration of the specific types of shared knowledge and shared beliefs required for the successful delivery of integrated care, as outlined by Evans and Baker [9]. L2L may have a reinforcing relationship with relational coordination, such that strengthening relational coordination contributes to L2L capacity, and vice versa. Reflection and self-directed learning processes are not explicitly incorporated into the concept of relational coordination, though they play an integral role in achieving shared goals, shared knowledge and mutual respect. Further work is needed to explore the relationships among L2L, relational coordination, and the integration of health and social care.

Traditional organizational hierarchies designed to achieve top-down control may be problematic in the implementation of our proposed framework. According to CAS theory, patterns of order emerge from an interactive dynamic as individuals and teams struggle with interdependency and create bottom-up pressures within organized organizational frameworks. This bottom-up pressure exerted by the self-organizing phenomenon of CAS may create tension between the formal organization and the emergent patterns of new order, threatening those in power in their attempt to maintain control [143]. This dynamic is particularly relevant to organizational efforts to enhance L2L behaviours. Collaboration among diverse actors, transformative feedback, critical reflection, and self-directed learning are designed to highlight alternative ways of knowing and practicing; these behaviours may also highlight existing power relations, potentially mobilizing those in power against L2L processes and related practice innovation [144]. L2L may thus be pursued in the service of collective learning and improvement, and in the service of compliance and control. Additional research is needed to explore the themes of power, politics and ethics in organizational and professional learning [143] as well as in inter-organizational and inter-professional learning [144] where conflicts and power imbalances may be more pronounced.

Traditional epistemology and methodology which advocates the objective separation between the research and the researched is not conducive to the spontaneous and improvisational nature of collective human action and thus to complex responsive processes of relating [145]. To provide a framework that explains the processes of complex social interaction requires adopting methodological approaches which support a relationality orientation to research, capturing the interrelated and 
interdependent patterns of relationships embedded in the specific context of interactions [146]. Relationality refers to a research orientation that engages participants in the process of analysis through reflexivity of self, circumstances, and others, and requires dialogue and reflective conversation for the researcher to understand both subjective and objective views simultaneously in their embedded context [147,148]. Adopting methods that are designed to capture relational aspects involves recognition of the significance of reflexivity and engagement with the subject of research by exploring the participants' narrative accounts in terms of relationships embedded in their social and historical context.

An elaborate tool to use is Evocative Inquiry which seeks viewpoints and stories through journal entries, anecdotes, case studies, video diaries and open ended surveys; the aim is to capture rich descriptions of what is happening or has happened, and to facilitate systems thinking [149]. The Kellogg Foundation also offers three evaluation designs, namely exploration, self-organizing and intuitive renewal, as methods for supporting a relational orientation to evaluation [150]. Exploration design is used for disorderly, un-predictable, un-patterned and not well understood phenomena and uses open-ended interviews, focus groups, on-sight observations, and investigative journalism techniques with snowball sampling to facilitate capturing inter-relationships. Self-organizing design is based on the principle of self-organization in complex systems, whereby, the development of relating patterns emerge without being externally imposed and not anticipated by the members of the system [151]. Here changing patterns are identified by focusing on diversity of relationships, values, roles and contextual conditions through dynamic models that examine variation over time [152]. Contradictions and deviance from the norm are identified further and investigated through focus groups, interviews, blogs, story-telling and reflective interviews. Finally, initial renewal design focuses on shifts in perspective, philosophy or institutional logic through reflection as a collective process, including significant milestone reviews, action reflection cycles, retrospective developmental evaluation and self-organizing models focusing on how order is created in the system [146,152]. In addition to these methods, Poole and his colleagues offer a process approach which aims to recognize and consider discrete events (i.e., a change or developmental process in an organization), event sequences, interdependencies among events, and patterns that integrate narrative explanations of events; suggested research methods include event coding, stochastic modeling, phasic analysis, time series analysis and nonlinear modeling [153]. Additional analytic techniques for examining nonlinear dynamics in systems include recurrence analysis, spatial fractal analysis and symbolic dynamics, among others [154].

Using the aforementioned methods, future research should explore how interdisciplinary professionals learn with, from, and about each other (or fail to do so) in the delivery of integrated care. We need to understand: (a) how health care professionals define each other's roles across health care settings, based on expectations, patterns of interactions, knowledge and values: (b) how institutional context fosters interaction (or not) between individuals working together on inter-dependant tasks, (c) how health care professionals influence each other's interactions in co-creating their futures of how they work and function together, and (d) the influence of interaction, feedback, reflection and self-directed learning on collective learning and collaboration. Incorporating into these research foci the views and experiences of patients and their caregivers will also provide valuable insights into learning and collaboration at the point of care. 
Future studies can validate the framework we have proposed which has the potential to facilitate integration planning and design efforts or to stimulate discussion regarding how to incorporate opportunities for building the L2L competency into existing ways of teaching, learning and working. Managers and leaders may also use the framework to consider, in dialogue with others, which forms of interaction, feedback, reflection, and self-directed learning best describe their team, program, organization, or network. This process of self-diagnosis may, in turn, be used to help incorporate new structures, processes, or interventions to enhance these learning capacities.

In conclusion, our view departs from conventional wisdom, and draws on CAS theory to argue that integrating care services is not about design principles and policies, but rather about the social and relational aspects of knowledge exchange and learning within social networks. Central to this perspective is the understanding that organizational settings and organization members influence each other, and are influenced in turn through interrelations and not simply through design principles and rules that act upon individuals or groups. In this paper, we have shifted attention to the cognitive and social dynamics of learning and suggest that the capacity to learn rather than the capacity to predict can facilitate the emergence of innovative delivery models for integrated care.

\section{Conflict of Interest}

The authors declare no conflict of interest.

\section{References}

1. Ham, C.; Curry, N. Clinical and Service Integration: The Route to Improved Outcomes; The King's Fund: London, UK, 2010.

2. Shortell, S.; Gillies, R.; Anderson, D.; Mitchell, J.; Morgan, K. Creating organized delivery systems: The barriers and facilitators. Hosp. Health Serv. Adm. 1993, 38, 447-466.

3. Singer, S.; Burgers, J.; Friedberg, M.; Rosenthal, M.; Leape, L.; Schneider, E. Defining and measuring integrated patient care: Promoting the next frontier in health care delivery. Med. Care Res. Rev. 2011, 68, 112-127.

4. Glouberman, S.; Mintzberg, H. Managing the care of health and the cure of disease-Part 1: Differentiation. Health Care Manage. Rev. 2001, 26, 56-69.

5. Orlikowski, W. Knowing in practice: Enacting a collective capability in distributed organizing. Organ. Sci. 2002, 13, 249-273.

6. Wenger, E. Communities of practice: Learning as a social system. Syst. Thinker 1998, 9, 225-246.

7. Anand, N.; Gardner, H.; Morris, T. Knowledge-based innovation: Emergence and Embedding of new practice areas in management consulting firms. Acad. Manage. J. 2007, 50, 406-428.

8. Barnsley, J.; Lemieux-Charles, L.; McKinney, M. Integrating learning into integrated delivery systems. Health Care Manage. Rev. 1998, 23, 18-28.

9. Evans, J.; Baker, R. Shared mental models of integrated care: Aligning multiple stakeholder perspectives. J. Health Organ. Manag. 2012, 26, 713-736.

10. van Wijngaarden, J.; de Bont, A.; Huijsman, R. Learning to cross boundaries: The integration of a health network to deliver seamless care. Health Pol. 2006, 79, 203-213. 
11. Fincham, R.; Forbes, T. Inter-professional Rivalry and Knowledge Integration: Problems in the Delivery of Integrated Mental Health Care. Proceedings of ProPEL Conference: Professions and Professional Learning in Troubling Times: Emerging Practices and Transgressive Knowledges,Stirling University, Stirling, UK, 9-11 May 2012.

12. Visse, M.; Widdershoven, G.; Abma, T. Moral learning in an integrated social and healthcare service network. Health Care Anal. 2012, 20, 281-296.

13. Williams, P. Integration of health and social care: A case of learning and knowledge management. Health Soc. Care Community. 2012, 2095, 550-560.

14. Kodner, D. All together now: A conceptual exploration of integrated care. Healthc. Q. 2009, 13, 6-15.

15. Suter, E.; Oelke, N.; Adair, C.; Armitage, G. Ten Key principles for successful health systems integration. Healthc. Q. 2009, 13, 16-23.

16. Browne, G.; Kingston, D.; Grdisa, V.; Markle-Reid, M. Conceptualization and measurement of integrated human service networks for evaluation. Int. J. Integr. Care 2007, 7, 1-6.

17. Devers, K.; Shortell, S.; Gillies, R.; Anderson, D.; Mitchell, J.; Erickson, K. Implementing organized delivery systems: An integration scorecard. Health Care Manage. R. 1994, 19, 7-20.

18. Gillies, R.; Shortell, S.; Anderson, D.; Mitchell, J.; Morgan, K. Conceptualizing and measuring integration: Findings from the health systems integration study. Hosp. Health Serv. Adm. 1993, 38, 467-489.

19. Lukas, C.; Meterko, M.; Lowcock, S.; Donaldson-Parlier, R.; Blakely, M.; Davies, M.; Petzel, R. Monitoring the progress of system integration. Qual. Manag. Health Care 2002, 10, 1-11.

20. Minkman, M.; Ahaus, K.; Fabbricotti, I.; Nabitz, U.; Huijsman, R. A quality management model for integrated care: Results of a delphi and concept mapping study. Int. J. Qual. Health C. 2008, 21, 66-75.

21. Minkman, M.; Ahaus, K.; Huijsman, R. A four phase development model for integrated care services in the Netherlands. BMC Health Serv. Res. 2009, 9, 42.

22. Salomon, G., Ed. Distributed Cognitions: Psychological and Educational Considerations; Cambridge University Press: New York, NY, USA, 1993.

23. McDaniel, R.; Driebe, D. Complexity Science and Health Care Management. In Advances in Health Care Management; Blair, J.D., Fottler, M.D., Savage, G.T., Eds.; Emerald Group Publishing: Bingley, UK, 2002; Volume 2, pp. 11-36.

24. Olson, E.E.; Eoyang, G.H. Facilitating Organization Change: Lessons from Complexity Science; Jossey-Bass/Pfeiffer: San Francisco, CA, USA, 2001.

25. Ferlie, E.; Fitzgerald, L.; Wood, M.; Hawkins, C. The nonspread of innovations: The mediating role of professionals. Acad. Manage. J. 2005, 48, 117-134.

26. Carlile, P. Transferring, Translating and transforming: An integrative framework for managing knowledge across boundaries. Organ. Sci. 2004, 15, 555-568.

27. Elwyn, G.; Taubert, M.; Kowalczuk, J. Sticky knowledge: A possible model for investigating implementation in healthcare contexts. Implement. Sci. 2007, 2, 44.

28. Swan, J.; Scarbrough, H.; Robertson, M. The construction of communities of practice in the management of innovation. Manage. Learn. 2002, 33, 477-496.

29. Argyris, C. Strategy, Change and Defensive Routines; Pitma: Boston, MA, USA, 1985. 
30. Tsoukas, H. A dialogical approach to the creation of new knowledge in organizations. Organ. Sci. 2009, 20, 941-957.

31. Denis, J.; Lamothe, L.; Langley, A.; Breton, M.; Gervais, J.; Trottier, L.; Contandriopoulos, D.; Dubois, C. The reciprocal dynamics of organizing and sense-making in the implementation of major public-sector reforms. Can. Public Adm. 2009, 52, 225-248.

32. Friedman, L.; Goes, J. Why integrated health networks have failed. Front. Health Serv. Manage. 2001, 17, 3-54.

33. Williams, P.; Sullivan, H. Faces of Integration. Int. J. Integr. Care 2009, 9, e100.

34. Pate, J.; Fischbacher, M.; Mackinnon, J. Health improvement: Countervailing pillars of partnership and profession. J. Health Organ. Manag. 2010, 24, 200-217.

35. Bloom, S.W. Structure and ideology in medical education: An analysis of resistance to change. J. Health Soc. Behav. 1988, 29, 294-306.

36. Bevan, G.; Janus, K. Why hasn't integrated health care developed widely in the United States and not at all in England? J. Health Polit. Policy Law 2011, 36, 141-164.

37. Hudson, B. Ten years of jointly commissioning health and social care in England. Int. J. Integr. Care 2011, 11, e005.

38. Jiwani, I.; Fleury, M. Divergent models of integration: The Canadian way. Int. J. Integr. Care 2011, 11, e018.

39. Edgren, L. The meaning of integrated care: A systems approach. Int. J. Integr. Care 2008, 8, e68.

40. Edgren, L.; Barnard, K. Complex adaptive systems for management of integrated care. Leadersh. Health Serv. 2012, 25, 39-51.

41. Nugus, P.; Carroll, K.; Hewett, D.; Short, A.; Forero, R.; Braithwaite, J. Integrated care in the emergency department: A complex adaptive systems perspective. Soc. Sci. Med. 2010, 71, 1997-2004.

42. Tsasis, P.; Evans, J.; Owen, S. Reframing the challenges to integrated care: A complex-adaptive systems perspective. Int. J. Integr. Care 2012, 12, e190.

43. Waldrop, M. Complexity: The Emerging Science at the Edge of Order and Chaos; Simon and Shuster: New York, NY, USA, 1992.

44. Plsek, P.; Greenhalgh, T. The challenge of complexity in health care. Brit. Med. J. 2001, 323, 625-628.

45. Stacey, R. The emergence of knowledge in organizations. Emergence 2000, 2, 23-39.

46. Wallis, S. Emerging order in CAS theory: Mapping some perspectives. Kybernetes 2008, 37, 1016-1029.

47. Vygotsky, L.S. The Collected Works of L.S. Vygotsky, Vol. 5; Rieber, R.W., Hall, M.J., Eds.; Plenum Press: New York, NY, USA, 1998.

48. Edwards, A. Keynote Presentation: Theorizing the New Partnership Landscape. In Teacher Education Advancement Network and the Association for Partnership in Education Conference; University of Cumbria: London, UK, 12 March 2013.

49. Capra, F. The Web of Life; Anchor Books: New York, NY, USA, 1996.

50. Meek, J.; De Ladurantey, J.; Newell, W. Complex systems, governance and policy administration consequences. Emergence Complexity Organ. 2007, 9, 24-36. 
51. Boisot, M.; McKelvey, B. Integrating modernist and postmodernist perspectives on organizations: a complexity science bridge. Acad. Manage. Rev. 2010, 35, 415-433.

52. Laihonen, H. Knowledge flows in self-organizing processes. J. Knowl. Manag. 2006, 10, 27-135.

53. Lanham, H.; Leykum, L.; Taylor, B.; McCannon, C.; Lindberg, C.; Lester, R. How complexity science can inform scale-up and spread in health care: Understanding the role of self-organization in variation across local contexts. Soc. Sci. Med. 2012, ID: 22819737.

54. Comfort, L. Self-organization in Complex Systems. J. Publ. Adm. Res. Theor. 1994, 4, 393-410.

55. Begun, J.; Zimmerman, B.; Dooley, K. Health Care Organizations as Complex Adaptive Systems. In Advances in Health Care Organization Theory; Mick, S.M., Wyttenbach, M., Eds.; Jossey-Bass: San Francisco, CA, USA, 2003; pp. 253-288.

56. Arrow, H.; Henry, K.B. Using complexity to promote group learning in healthcare. J. Eval. Clin. Practice, 2010, 16, 861-866.

57. Heylighen, F. Self-organization in Communicating Groups: The Emergence of Coordination, Shared References and Collective Intelligence. In Language and Complexity; Barcelona University Press: Barcelona, Spain, 2011.

58. Weick, K.E. Sensemaking in Organizations; Sage Publications: Thousand Oaks, CA, USA, 1995.

59. Guastello, S.J. Self-organization and leadership emergence in emergency response teams. Nonlinear Dynamics Psychol. Life Sci. 2010, 14, 179-204.

60. Griffin, D.; Shaw, P.; Stacey, R. Knowing and acting in conditions of uncertainty: A complexity perspective. Syst. Pract. Act. Res. 1999, 12, 295-309.

61. Kitson, A. The need for systems change: Reflections on knowledge translation and organizational change. J. Adv. Nurs. 2009, 65, 217-228.

62. Lindberg, C.; Schneider, M. Leadership in a Complex Adaptive System: Insights from Positive Deviance. Academy of Management Best Paper Proceedings, Boston, MA, USA, 2012.

63. Suchman, A; Sluyter, D.; Williamson, P. Leading Change in Healthcare: Transforming Organizations Using Complexity, Positive Psychology and Relationship-Centered Care; Radcliffe Publishing: London, UK, 2011.

64. Greenhalgh, T.; Wieringa, S. Is it time to drop the 'Knowledge Translation' Metaphor? A critical review. J. R. Soc. Med. 2011, 104, 501-509.

65. Cook, S.D.N.; Brown, J.S. Bridging epistemologies: The generative dance between organizational knowledge and organizational knowing. Organ. Sci. 1999, 10, 381-400.

66. Berger, P.; Luckmann, T. The Social Construction of Reality: A Treatise in the Sociology of Knowledge; Doubleday \& Company: Garden City, NY, USA, 1966.

67. Bourdieu, P. Outline of a Theory of Practice; Cambridge University Press: Cambridge, UK, 1977.

68. Dewey, J. Experience and Education; Kappa Delta Pi: New York, NY, USA, 1938.

69. Boland, R., Jr.; Tenkasi, R. Perspective making and perspective taking in communities of knowing. Organ. Sci. 1995, 6, 350-372.

70. Brown, J.; Duguid, P. Organizational learning and communities-of-practice: Toward a unified view of working, learning and innovation. Organ. Sci. 1991, 2, 40-57.

71. Rush, L.; Diamond, J. Exploring Key Variations and Meanings in Understanding Intra-organisational Collaboration at One University. Proceedings of SRHE Conference, Celtic Manor, UK, 12 December 2009; Birmingham City University: Birmingham, UK, 2009. 
72. Watkins, C. Learning about Learning Enhances Performance; Research Matters Series No. 13; Institute of Education: London, UK, 2002.

73. Claxton, G. Expanding the Capacity to Learn: A New End for Education? Proceedings of British Educational Research Association Annual Conference, Warwick University, UK, 6 September 2006.

74. Vaill, P. Learning as a Way of Being: Strategies for Survival in a World of Permanent White Water; Jossey-Bass: San Francisco, CA, USA, 1996.

75. Axelrod, R.; Cohen, M. Harnessing Complexity: Organizational Implications of a Scientific Frontier; Basic Books: New York, NY, USA, 2000.

76. Flavell, J. Metacognition and cognitive monitoring: A new era of cognitive-developmental inquiry. Am. Psychol. 1979, 34, 906-911.

77. Deakin-Crick, R. Learning how to learn: The dynamic assessment of learning power. Curriculum J. 2007, 18, 135-153.

78. Bransford, J., Brown, A., Cocking, R., Eds. How People Learn: Brain, Mind, Experience, and School; National Academy Press: Washington, DC, USA, 2000.

79. Suchman, A. A new theoretical foundation for relationship-centered care: Complex responsive processes of relating. J. Gen. Intern. Med. 2006, 21, S40-S44.

80. Mezirow, J.; Marswick, V. Education for Perspective Transformation: Women's Re-entry Programs in Community Colleges; Teachers College, Columbia University: New York, NY, 1978.

81. Kegan, R. What "form” transforms? A Constructive-Developmental Approach to Transformative Learning. In Contemporary Theories of Learning: Learning Theorists in Their Own Words; Illeris, K., Ed.; Routledge: New York, NY, USA, 2009.

82. Meyer, J.; Land, R. Threshold Concepts and Troublesome Knowledge: Linkages to Ways of Thinking and Practising Within the Disciplines. In Improving Student Learning: Improving Student Learning Theory and Practice-Ten Years On; Rust, C., Ed.; Oxford Centre for Staff and Learning Development: Oxford, UK, 2003.

83. Rush, L. Expanding the Capacity to Learn in ITT: A Personal Reflection on Embedding and Enacting a Distinct Pedagogic Approach to Partnership Learning. Proceedings of BERA Conference, University of Warwick, Coventry, UK, 1-3 September 2010; University of Warwick: Coventry, UK, 2010.

84. Rush, L.; Diamond, J. New Professionalism and Public Sector Management: A Reflection on Collaborative Practice in UK Teacher Education. Proceedings of XVI Annual Conference of the International Research Society for Public Management, University of Rome, Rome, Italy, 2012.

85. Claxton, G. Cultivating Positive Learning Dispositions. In The Routledge Companion to Education; Daniels, H., Lauder, H., Porter, J., Eds.; Routledge: London, UK, 2008.

86. Merriam, S.; Caffarella, R. Learning in Adulthood: A Comprehensive Guide, 2nd ed.; Jossey-Bass: San Francisco, CA, USA, 1999.

87. Mezirow, J. Learning as Transformation: Critical Perspectives on a Theory in Progress; Jossey-Bass: San Francisco, CA, USA, 2000.

88. Carley, K.; Hill, V. Structural change and learning within organizations. In Dynamics of Organizations: Computational Modeling and Organization Theories; Larsen, E.R., Ed.; MIT Press: Menlo Park, CA, USA, 2001; pp. 63-92. 
89. Hedegaard, M. Analyzing children's learning and development in everyday settings from a cultural-historical wholeness approach. Mind Cult. Activ. 2012, 19, 127-138.

90. Vygotsky, L. Thought and Language; MIT Press: Cambridge, MA, USA, 1962.

91. Vygotsky, L. Mind in Society: The Development of Higher Psychological Processes; Harvard University Press: Boston, MA, USA, 1978.

92. Bailey, D.; Koney, K. Strategic Alliances among Health and Human Services Organizations: From Affiliations to Consolidations; Sage Publications: Thousand Oaks, CA, USA, 2000.

93. Griffiths, M.; Tann, S. Using reflective practice to link personal and public theories. J. Educ. Teaching 1992, 18, 69-84.

94. Grow, G. Teaching learners to be self-directed. Adult Educ. Quart. 1991, 41, 125-149.

95. Miller, J.; Seller, W. Curriculum: Perspectives and Practice; Longman: New York, NY, USA, 1990.

96. Biggs, J. Teaching for Quality Learning at University: What the Student Does; Society for Research into Higher Education, Open University Press: Philadelphia, PA, USA, 1999.

97. Pollard, A., Bourne, J., Eds. Teaching and Learning in the Primary School; Routledge: New York, NY, USA, 1994.

98. Delamont, S. Interaction in the Classroom; Methuen: London, UK, 1983.

99. Gajda, R. Utilizing collaboration theory to evaluate strategic alliances. Am. J. Eval. 2004, 25, 65-77.

100. Stryker, S.; Statham, A. Symbolic Interaction and Role Theory. In Handbook of Social Psychology, 3rd ed.; Lindzey, G., Aronson, E., Eds.; Random House: New York, NY, 1985; Volume 1, pp. 311-378.

101. Wrzesniewski, A.; Dutton, J.E.; Debebe, G. Interpersonal sensemaking and the meaning of work. Res. Organ. Behav. 2003, 25, 93-135.

102. Wegner, D.M.; Giuliano, T.; Hertel P.T. Cognitive Interdependence in Close Relationships. In Compatible and Incompatible Relationships; Ickes, W.J., Knowles, E.S., Eds.; Springer-Verlag: New York, NY, 1985; pp. 253-276.

103. Liang, D.; Moreland, R.; Argote, L. Group versus individual training and group performance: the mediating role of group transactive memory. Pers. Soc. Psychol. B 1995, 21, 384-393.

104. Weick, K.; Roberts, K. Collective mind in organizations: Heedful interrelating on flight decks. Adm. Sci. Q. 1993, 38, 357-381.

105. Faraj, S.; Xiao, Y. Coordination in fast response organizations. Manage. Sci. 2006, 52, 1155-1169.

106. Tan, J.; Wen, H.; Awad, N. Health care and service delivery systems as complex adaptive systems. Comm. ACM 2005, 48, 36-44.

107. Bechky, B. Sharing meaning across occupational communities: The transformation of understanding on a production floor. Organ. Sci. 2003, 14, 312-330.

108. Ling, T.; Brereton, L.; Conklin, A.; Newbould, J.; Roland, M. Barriers and facilitators to integrating care: Experiences from the English integrated care pilots. Int. J. Integr. Care 2012, 12, e129.

109. Reid, B. But we're doing it already: Exploring a response to the concept of reflective practice in order to improve its facilitation. Nurs. Educ. Today 1993, 13, 305-309. 
110. Hatton, N.; Smith, D. Reflection in teacher education: Towards definition and implementation. Teach. Teach. Educ. 1995, 11, 33-49.

111. Eoyang, G.; Holladay, R. Adaptive Action: Leveraging Uncertainty in Your Organization; Stanford University Press: Palo Alto, CA, USA, 2013.

112. Gustafsson, C.; Fagerberg, I. Reflection, the way to professional development? J. Clin. Nurs. 2004, 13, 271-280.

113. Schon, D. The Reflective Practitioner: How Professionals Think in Action; Basic Books: New York, NY, USA, 1983.

114. Mann, K.; Gordon, J.; MacLeoid, A. Reflection and reflective practice in health professions education: A systematic review. Adv. Health Sci. Educ. 2009, 14, 595-621.

115. L'Aigulle, Y. Pushing Back the Boundaries of Personal Experience. In Reflective Practice in Nursing: The Growth of the Professional Practitioner; Palmer, A.M., Burns, S., Bulman, C., Eds.; Blackwell Scientific Publications: London, UK, 1994.

116. Driscoll, J. Reflective practice for practice: A framework of structured reflection for clinical areas. Sr. Nurse 1994, 13, 47-50.

117. Fisher, R. Teaching Children to Think; Basil Blackwell: Oxford, UK, 1990.

118. Freeman, J. Educating the Very Able: Current International Research; Ofsted Reviews of Research, Office for Standards in Education: London, UK, 1998.

119. Ames, G.; Ames, K. Report on Teaching at the Center for Environmental Management and Planning. In Georgian Academy of Sciences, Faculty Series FS93-06, Tbilisi, Republic of Georgia, 1-26 October 1992; Department of Agricultural and Applied Economics, University of Georgia: Athens, Greece, 1993.

120. Dweck, C.; Leggett, E. A social- cognitive approach to motivation and personality. Psychol. Rev. 1988, 95, 256-273.

121. Nicholls, J.G. The Competitive Ethos and Democratic Education; Harvard University Press: Cambridge, MA, USA, 1989.

122. Mortimore, P., Ed. Understanding Pedagogy and Its Impact on Learning; Paul Chapman: London, UK, 1999.

123. Colthart, I.; Bagnall, G.; Evans, A.; Allbutt, H.; Haig, A.; Illing, J.; McKinstry, B. The effectiveness of self-assessment on the identification of learner needs, learner activity, and impact on clinical practice: BEME Guide No. 10. Med. Teach. 2008, 30, 124-145.

124. Bleakley, A. Social comparison, Peer learning and democracy in medical education. Med. Teach. 2010, 32, 878-879.

125. Bleakley, A. Broadening conceptions of learning in medical education: The message from team working. Med. Educ. 2006, 40, 150-157.

126. Eva, K.; Regehr, G. Self-assessment in the health professions: A reformulation and research agenda. Acad. Med. 2005, 80, S46-S54.

127. Benneworth, P. Leading Innovation: Building Effective Regional Coalitions for Innovation; NESTA: London, UK, 2007.

128. Harris, A. Distributed leadership: According to the evidence. J. Educ. Admin. 2008, 46, 172-188.

129. Karlsson, J.; Anderberg, E.; Booth, S.; Odenrick, P.; Christmansson, M. Reaching beyond disciplines through collaboration. J. Workplace Learn. 2008, 20, 98-113. 
130. Whitchurch, C. Professional Managers in UK Higher Education: Preparing for Complex Futures-Final Report; Leadership Foundation for Higher Education: London, UK, 2008.

131. Greeno, J.G. Theories and practices of thinking and learning to think. Am. J. Educ. (Chic Ill) 1997, 106, 85-126.

132. Greeno, J.G. Learning in Activity. In The Cambridge Handbook of the Learning Sciences; Sawyer, R., Ed.; Cambridge University Press: Cambridge, UK, 2006; pp. 79-96.

133. Kodner, D.; Spreeuwenberg, C. Integrated care: Meaning, logic, applications, and implicationsa discussion paper. Int. J. Integr. Care 2002, 2, e12.

134. Kauffman, S.A. At Home in the Universe: The Search for the Laws of Self-Organization and Complexity; Oxford University Press: Oxford, UK, 1995.

135. Stacey, R.D. Strategic Management and Organizational Dynamics: The Challenge of Complexity; 4th ed.; Pearson Education/Prentice Hall: Harlow, UK, 2003.

136. Weick, K.E. Making Sense of the Organization; Blackwell Publishing: Malden, MA, USA, 2001.

137. Morgan, G. Images of Organization; Sage Publications: Thousand Oaks, CA, USA, 2007.

138. Cilliers, P. Complexity and Postmodernism: Understanding Complex Systems; Routledge: London, UK, 1998.

139. Poerksen, B. Learning how to learn. Kybernetes 2005, 34, 471-484.

140. Mezirow, J. Transformative Dimensions of Adult Learning; Jossey-Bass: San Francisco, CA, USA, 1991.

141. Gittell, J. Coordinating mechanisms in care provider groups: Relational coordination as a mediator and input uncertainty as a moderator of performance effects. Manage. Sci. 2002, 48, 1408-1426.

142. Gittell, J.; Fairfield, K.; Bierbaum, B.; Head, W.; Jackson, R.; Kelly, M.; Laskin, R.; Lipson, S.; Siliski, J.; Thornhill, T.; et al. Impact of relational coordination on quality of care, postoperative pain and functioning, and length of stay: A nine-hospital study on surgical patients. Med. Care 2000, 38, 807-819.

143. Easterby-Smith, M.; Snell, R.; Gherardi, S. Organizational learning: Diverging communities of practice? Manag. Learn. 1998, 29, 259-272.

144. Mork, B.; Hoholm, T.; Ellingsen, G.; Edwin, B.; Aanestad, M. Challenging expertise: On power relations within and across communities of practice in medical innovation. Manag. Learn. 2010, 41, 575-592.

145. Layder, D. The Realist Image in Social Science; MacMillan: London, UK, 1990.

146. Patton, M.Q. Systems Thinking and Complexity Concepts for Developmental Evaluation in Developmental Evaluation: Applying Complexity Concepts to Enhance Innovation and Use; The Guilford Press: New York, NY, USA, 2011.

147. Bradbury, H.; Lichenstein, B.M.B. Relationality in organizational research: Exploring the space between. Organ. Sci. 2000, 11, 551-564.

148. Czarniawska, B. A Theory of Organizing; Edward Elgar Publishing: Cheltenham, UK, 2008.

149. Grove, J.; Barry, K.; Haas, T. EvaluLead: A Guide for Shaping and Evaluating Leadership Development Programs; The Public Health Institute: California, CA, USA, 2005.

150. W.K. Kellogg Foundation. Designing Initiative Evaluation a Systems-oriented Framework for Evaluating Social Change Efforts; W.K. Kellogg Foundation: Battle Creek, MI, USA, 2007. 
151. Stacey, R.D. Complex Responsive Processes in Organizations: Learning and Knowledge Creation; Routledge: London, UK, 2001.

152. Dooley, K. Complexity Science Models of Organizational Change and Innovation. In Handbook of Organizational Change and Innovation; Poole, M.S., Van de Ven, A. Eds.; Oxford University Press: Oxford, UK, 2004.

153. Poole, M.; Van De Ven, A.H.; Dooley, K. Organizational Change and Innovation Processes: Theory and Methods for Research; Oxford University Press: New York, NY, USA, 2000.

154. Guastello, S., Gregson, R., Eds. Nonlinear Dynamical Systems Analysis for the Behavioral Sciences using Real Data; CRC Press: Boca Raton, FL, USA, 2011.

(c) 2013 by the authors; licensee MDPI, Basel, Switzerland. This article is an open-access article distributed under the terms and conditions of the Creative Commons Attribution license (http://creativecommons.org/licenses/by/3.0/). 